\title{
IDEAS Y VIDAS A TRAVÉS DEL ATLÁNTICO. EL ANARQUISMO AMERICANO EN LA PRENSA LIBERTARIA GALLEGA
}

\section{Ideas and lives across the Atlantic. The American Anarchism in the Galician libertarian press}

\author{
ÓSCAR FREÁN HERNÁNDEZ \\ Université Lumière Lyon 2 \\ oscar.frean-hernandez@univ-lyon2.fr
}

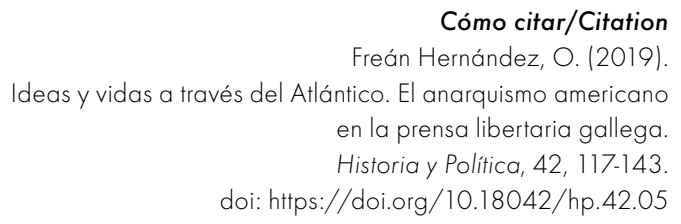

(Recepción: 26/10/2018; evaluación: 19/01/2019; aceptación: 07/06/2019; publicación: 13/12/2019)

Resumen

En este artículo se analiza la presencia del anarquismo americano en la prensa libertaria gallega hasta 1936 desde la perspectiva de la historia transnacional. Las migraciones transatlánticas de los siglos XIX y Xx favorecieron el desarrollo de una densa red de relaciones y contactos entre Galicia y los países americanos. En esta red participan militantes anarquistas de ambos lados del océano. Los anarquistas gallegos mantienen una estrecha colaboración con sus compañeros libertarios americanos y muchos militantes gallegos participan activamente en el movimiento obrero de sus países de acogida. La prensa libertaria gallega muestra esta relación y participación de diferentes maneras (artículos, colaboraciones, noticias, iniciativas de apoyo y solidaridad, etc.). Esto prueba la existencia de una intensa circulación de ideas y de personas, así como de una militancia transnacional en el ámbito atlántico. 


\title{
Palabras clave
}

Anarquismo; historia transnacional; prensa; Galicia; América.

\begin{abstract}
In this article we will analyse, from a transnational history point of view, the presence of American anarchism in the Galician libertarian press until 1936. In the 19 th and $20 \mathrm{~h}$ centuries, the transatlantic migrations contributed to develop a dense network of contacts and relationships between Galicia and American countries. This network involves anarchist militants on both sides of the Ocean. The Galician anarchists have a close collaboration with her Americans libertarian comrades; and many Galician militants are actively committed in the labour movement of their host countries. The Galician libertarian press shows this relationship and this participation in different ways (articles, contributions, news, solidarity initiatives, etc.). That proves the existence of an intense circulation of ideas and persons, as well as a transnational militancy in the Atlantic area.
\end{abstract}

\section{Keywords}

Anarchism; transnational history; press; Galicia; America. 


\section{SUMARIO}

I. INTRODUCCIÓN. II. LA PRENSA OBRERA EN GALICIA. III. LAS COLABORACIONES QUE LOS MILITANTES GALLEGOS ENVIABAN A LA PRENSA DESDE AMÉRICA. IV. LOS ARTÍCULOS DE LA PRENSA Y DE LOS MILITANTES AMERICANOS REPRODUCIDOS EN LOS PERIÓDICOS LIBERTARIOS GALLEGOS. V. LAS NOTAS BREVES E INFORMACIONES DESDE AMÉRICA. VI. LAS INICIATIVAS DE APOYO SOLIDARIO. VII. LA CORRESPONDENCIA Y LAS NOTAS ADMINISTRATIVAS. VIII. CONCLUSIONES. BIBLIOGRAFÍA.

\section{INTRODUCCIÓN}

Para los gallegos y una buena parte de los americanos el océano Atlántico es un espacio común entre dos continentes, un lugar de tránsito y de trabajo, un límite físico y psicológico que une a unos pueblos y a unos países marcados por un pasado y un presente de frecuentes contactos y estrechas relaciones. Personas de diferente clase y condición, de distintas ideas y de orígenes diversos vivieron, y viven, esta presencia del Atlántico en sus vidas, bien por experiencias en primera persona, bien por los relatos escritos u orales que sus familiares, amigos y vecinos les hacían llegar sobre las tierras más allá del océano. En el presente trabajo vamos a analizar un aspecto particular de estos profundos lazos que unieron a los habitantes de estos territorios: los intercambios y las transferencias expresados en la prensa entre los anarquistas gallegos $\mathrm{y}$ los de diferentes países americanos en el primer tercio del siglo xx hasta el inicio de la guerra civil española de 1936.

Durante este periodo la ideología anarquista jugó un destacado papel en los movimientos sociales y políticos de distintos países. Aunque en la mayoría de ellos el anarquismo empezó a declinar a partir de los ańos diez, en Argentina y en España el movimiento libertario prolongó su rica existencia durante las décadas siguientes, consiguiendo articular una sólida estructura sindical en torno a la Confederación Nacional del Trabajo (CNT) española y la Federación Obrera Regional Argentina (FORA). El militantismo anarquista superó, sin embargo, el ámbito del sindicalismo y fomentó un asociacionismo variado en forma de grupos, centros de estudio, escuelas, editoriales, periódicos, etc. En países como Brasil, Cuba, Estados Unidos, Uruguay y otros, la actividad de los anarquistas fue destacada, aunque sin llegar a crear unas organizaciones de masa como fueron las referidas centrales sindicales argentina y española. 
Este trabajo se inserta en la perspectiva de la llamada historia transnacional. La historia transnacional es un paradigma de análisis que surgió en los ańos noventa del siglo pasado en el marco de desarrollo de la historia global o mundial. Esta perspectiva de la investigación orienta la atención del historiador hacia «los intercambios, las interacciones, las redes y otros enfoques que ilustran los contactos y las reagrupaciones de ambos lados de las fronteras nacionales, entre culturas e incluso entre civilizaciones»; en ese sentido, va más allá de las relaciones entre Estados para «explorar temas que superan las fronteras nacionales, sin que ello suponga subestimar la existencia de naciones y la importancia de estudiar las relaciones entre nacional y transnacional ${ }^{1}$. En cierto modo, la perspectiva de la historia transnacional contesta la visión clásica y limitada de la historia nacional o de la historia nacionalista ${ }^{2}$.

Lo más interesante de la perspectiva transnacional es que permite integrar una nueva variable de lectura perfectamente compatible con los estudios locales o nacionales. Esta combinación de escalas entre lo subnacional y lo supranacional se adapta muy bien a diversos temas de investigación, y en particular al estudio del movimiento obrero y del anarquismo ${ }^{3}$. La construcción de la identidad de clase y el desarrollo de las culturas políticas —en nuestro caso la anarquista - no pueden entenderse sin tener en cuenta el marco internacional, la circulación de ideas y de personas y los múltiples intercambios transfronterizos.

El internacionalismo es uno de los principios básicos del movimiento obrero de clase y el anarquismo asume totalmente esta ambición de superación de los límites nacionales entre países. Además, entre las características fundamentales de la ideología anarquista están el antiestatismo, la oposición a la idea de Estado nación y la concepción de un mundo sin fronteras. Por esta razón, es muy difícil limitar los estudios sobre el anarquismo a un marco estrictamente nacional. El concepto de transnacional resulta así muy interesante para comprender las reflexiones teóricas, la mentalidad y la acción de los libertarios. Eso no nos debe hacer olvidar, sin embargo, el hecho de que en la práctica el movimiento anarquista actuara en el marco de unos Estados nación determinados y sus militantes y simpatizantes asumieran, de manera más o menos consciente, unas características identitarias propias a las de sus países de origen.

Los anarquistas integraron el internacionalismo libertario tanto en sus principios teóricos como en sus prácticas militantes. Esto es visible en el amplio

\footnotetext{
Iriye (2013).

Guardia, de la y Pan-Montojo (1998).

3 Sueiro Seoane (2013).
} 
abanico de contactos y de relaciones que los libertarios mantuvieron más allá de las fronteras de los países en los que vivían, así como en los constantes desplazamientos entre territorios por motivos diversos: búsqueda de trabajo, exilio, viajes de propaganda o de activismo. Por estas razones debemos considerar el anarquismo como un movimiento global y reticular con múltiples ramificaciones en el mundo y con una cohesión que supera ampliamente los límites de las fronteras nacionales.

La acción militante desarrollada por los libertarios favoreció la apertura y el contacto con personas de otros países y continentes. Las redes de contactos y de solidaridad tejidas por los anarquistas son así la prueba de una práctica militante que superaba, ampliamente, las fronteras nacionales. Eso no quiere decir, sin embargo, que los anarquistas tuviesen una sólida organización estructurada en el ámbito internacional. Al contrario, los contactos y relaciones entre libertarios de diferentes países eran bastante libres y no necesitaban de un cuadro institucional definido para existir. Por esa razón, la noción de red se adapta perfectamente a la acción transnacional de los anarquistas ${ }^{4}$.

El presente trabajo tiene como objetivo analizar esos lazos transnacionales de los anarquistas a través de la prensa libertaria gallega. Así, constatados los fuertes vínculos y los intensos intercambios existentes entre gallegos y americanos en los periódicos libertarios ${ }^{5}$, plantearemos una clasificación para comprender mejor cómo se operaba esta presencia internacional ultramarina en la prensa militante gallega.

Las relaciones y los lazos entre Galicia y los países de América se intensificaron de una manera muy importante desde finales del siglo XIX. En ese momento, uno de los fenómenos que más afectó a la economía y la sociedad gallegas fue el de la emigración. Una emigración que en ese periodo tenía como destino preferente los países americanos. La razón principal de esta emigración era económica, si bien había también emigrados que se marchaban del país por razones de tipo político o sindical - huyendo de ciertos episodios de represión-o militar - para evitar las quintas-. De todos modos, la emigración no era la panacea universal y las condiciones de trabajo y de integración no eran

4 Eso no fue óbice para la existencia de organizaciones libertarias supranacionales, por ejemplo la organización de una AIT libertaria en 1922 con el objetivo de organizar al conjunto de sindicatos anarcosindicalistas del mundo entero. Sin embargo, en la práctica esta organización tuvo grandes dificultades para funcionar y su actividad fue limitada.

5 Y en general entre la prensa obrera gallega y americana. Cf. Núñez Seixas (1998b): 573. 
fáciles. En ese sentido, alguna de las colaboraciones en la prensa obrera gallega intentaba dar un retrato veraz y desmitificador de la experiencia migratoria. Es el caso del semanario anarcosindicalista coruñés $\mathrm{La}$ Voz del Obrero, que en noviembre de 1913 denunciaba precisamente la mala situación de muchos emigrados en Argentina y hacía un llamamiento contra la emigración en general ${ }^{6}$.

\section{LA PRENSA OBRERA EN GALICIA}

Además de la emigración trasatlántica, otro fenómeno que se constata en Galicia en el primer tercio del siglo xx es el del desarrollo de un movimiento obrero organizado que consiguió abrirse un espacio importante y arraigar, especialmente en las ciudades del país, entre la masa de trabajadores ocupados en las industrias y en los servicios, así como en actividades primarias como la pesca, por ejemplo. En Galicia, anarquistas y socialistas dominaron ampliamente este movimiento. Para ellos, la prensa fue uno de los instrumentos fundamentales de difusión de sus principios políticos y sindicales, además de un medio utilizado para estimular las conciencias de los trabajadores, para movilizarlos en defensa de sus intereses y, en fin, para incitarlos a la lucha contra la burguesía, la Iglesia y el resto de clases y grupos dominantes.

El papel de la prensa obrera no fue anodino en Galicia. Entre 1866 y 1936 se publicaron un total de 119 cabeceras de este tipo de periódicos. Un tercio de estas publicaciones - 39- fueron de ideología libertaria. El número de estos periódicos libertarios fue bastante constante desde los años ochenta del siglo XIX, con ligeras variaciones en función de los periodos de represión sufridos por el obrerismo. Como era de esperar, fue en el periodo de la II República cuando el número de cabeceras fue más importante, en el que se alcanzaron 12 periódicos de orientación libertaria entre 1931 y julio de 1936. El marco de libertades y el aumento de la movilización política y sindical en los ańos treinta favorecieron este desarrollo general de la prensa y, en particular, el de los periódicos obreros.

Los diferentes contextos políticos, los momentos de conflictividad social y de represión condicionaron, obviamente, el trabajo de edición y de difusión de la prensa militante. De todos modos, eso no impidió la publicación continuada de este tipo de periódicos. De modo que, aparte de la relativa importancia numérica, es necesario también resaltar la estabilidad en el tiempo y la duración de algunas de estas publicaciones, así como su impacto más allá de las fronteras gallegas.

$6 \quad$ La Voz del Obrero, 12-11-1913, p. 2. 
Podemos así citar, como prueba de esta estabilidad, el caso del semanario coruñés Solidaridad Obrera — continuado con el título de Solidaridad desde 1935-, que fue publicado entre 1923 y 1936, con una interrupción entre 1928 y 1929. También fue destacable la estabilidad del semanario La Voz del Obrero, editado en A Coruña entre 1910 y 1920. En el siglo anterior, cabe mencionar el caso de El Corsario, publicado igualmente en esta ciudad entre 1890 y 1896 en su primera etapa. Desde el punto de vista cualitativo, debemos citar la destacada influencia tanto de El Corsario como del semanario vigués ;Despertad! en los debates vividos por el movimiento anarquista y anarcosindicalista español en los años noventa del siglo xix y en los años veinte del siglo xx. También relevante fue el semanario anarquista editado en A Coruña Brazo y Cerebro, en particular por su diversidad temática y por la introducción de contenidos «modernos» como la sexualidad o el feminismo, por ejemplo?.

Esta prensa libertaria era fundamentalmente urbana y tenía como principales lugares de edición las ciudades de A Coruña, Vigo y Ferrol; es decir, tres ciudades portuarias y comerciales, abiertas al Atlántico y punto de partida y llegada — sobre todo Vigo y A Coruña— de las compañías trasatlánticas que conectaban Galicia con los países americanos. Así que no resulta en absoluto extraño el hecho de encontrar en la prensa libertaria gallega referencias o informaciones sobre los países americanos, así como colaboraciones firmadas por militantes en América o por compañeros retornados.

Los puertos eran, de hecho, unos espacios abiertos al mundo que contribuyeron a alimentar la recepción de contactos y de influencias recibidas desde el extranjero. Estos contactos e influencias eran algo corriente en la vida cotidiana de los gallegos, de manera especial de aquellos que tenían en el mar su espacio de trabajo. El testimonio que nos hace de su niñez Emilio González López, hijo y nieto de anarquistas, es paradigmático de esta presencia tan habitual del mar y de otras tierras en la mentalidad de los gallegos:

Las casetas de los gabarreros eran el único punto de reunión, fuera de las tabernas, no sólo [...] para los gabarreros, sino para cuantos trabajaban en el puerto, entre ellos mi abuelo y mi padre [...]. Para mi, las casetas de los gabarreros [...] fueron como una ventana abierta al mundo del mar, no al mundo del mar de la bahía coruñesa [...], sino al de todos los mares y océanos por los que habían navegado la mayor parte de los que allí se reunían. Desfilaban por sus conversaciones

Para los datos sobre la prensa obrera gallega cf. Freán Hernández (2013). Debemos precisar que todos los periódicos citados fueron editados en Galicia, pues algunos títulos — como Solidaridad Obrera, Brazo y Cerebro o Despertad — podemos encontrarlos también en otros lugares del mundo. 
todos los principales puertos de los cinco continentes, desde Nueva York a Barcelona [...]. Eran una valiosa fuente de conocimiento de la vida, de la vida unida al mar; una fuente de conocimiento de amplias perspectivas, más viva que la que desfila por la mayor parte de las páginas de los libros. Eran como relatos de aventuras de modernos Simbad, el marino. Yo, que amaba el mar [...], el de la costa en que nací y me crié, lo veía ahora a través de estos relatos en la inmensidad y lejanía de los mares y océanos ${ }^{8}$.

En los intercambios entre Galicia y América debemos destacar a los militantes libertarios gallegos del gremio de los camareros marítimos; es decir, aquellos trabajadores que desarrollaban su actividad en los trasatlánticos que trasladaban a los emigrantes y que, por razones de organización de los viajes, hacían escala en diferentes puertos a lo largo de sus trayectos. Estos trabajadores tenían una cierta importancia en el movimiento obrero de la ciudad de A Coruña. Su sindicato, La Cosmopolita, había sido constituido en 1905 y en los ańos 1910 ya lo vemos integrado en la CNT. En 1919 contaba 200 afiliados, una cifra que se mantiene estable hasta 1934 , año en el que representaba a 180 trabajadores. Entre sus miembros podemos destacar las figuras de Ricardo Cotelo Palleiro y de Enrique Taboada Chás.

Otro ejemplo es el del militante de la CNT de Vigo Dalmacio Bragado, igualmente empleado como camarero en los trasatlánticos que cubrían las rutas a América del Sur'. El papel de estos militantes en los intercambios entre ambos lados del Atlántico fue ciertamente destacado, pues la facilidad de los desplazamientos les permitía tener una red de contactos en las ciudades portuarias donde arribaban y llevar de un puerto a otro periódicos, libros, panfletos y cualquier tipo de documentos.

Las huellas de los emigrantes gallegos entre América y Galicia son numerosas y variadas. En el caso del anarquismo que nos ocupa contamos con ejemplos de algunos emigrados que participaron activamente en el movimiento obrero y en el movimiento libertario. Los casos de activismo militante en el contexto de la emigración galaico-americana se produjeron en las dos direcciones: América-Galicia y Galicia-América. Podemos hablar así de aquellos trabajadores que descubrieron el asociacionismo y las ideologías obreras en América, se hicieron militantes en los países americanos y desarrollaron su

8 González López (1987): 41. Emilio González López (1903-1991) fue un activo político de la izquierda republicana gallega. Nació en el barrio marinero coruñés de San Roque de Afora y murió en Nueva York, lugar donde vivió exiliado desde el final de la guerra civil.

9 Sobre Dalmacio Bragado cf. Briallos (2003): 23-24. 
actividad tanto en estos países como en Galicia a su retorno —en el caso de los retornados-.

En el otro sentido, hay que citar a aquellos activistas que ya tenían una experiencia militante previa en Galicia y que van a continuar en el movimiento obrero y en el anarquismo en sus países de acogida. Muchos jamás retornaron de la emigración; otros realizaron trayectorias con idas y venidas a ambos lados del Atlántico. Además, una vez iniciada la guerra civil y la represión en 1936, América se convirtió en una de las vías de escape para aquellos militantes más activos que tuvieron la suerte y la oportunidad de escapar a la persecución dirigida por las nuevas autoridades franquistas ${ }^{10}$.

Con respecto a los retornados, fueron numerosos los que continuaron su labor asociativa militante en Galicia, contribuyendo así al desarrollo del movimiento anarquista gallego. Aunque no tengamos datos suficientemente representativos, se puede afirmar que estos retornados enriquecieron la acción colectiva en interacción con los militantes y las organizaciones preexistentes en Galicia, ya que, en la mayor parte de los casos, desarrollaron su labor en el marco asociativo previamente implantado que ellos contribuyeron a consolidar y a desarrollar. Su influjo parece que fue más evidente en las zonas rurales o semiurbanas, donde su presencia contribuyó a dinamizar la organización de los sindicatos de la $\mathrm{CNT}^{11}$.

Podemos citar algunos casos de algunos militantes gallegos muy activos en el movimiento anarquista americano. Por ejemplo, Antonio Soto Canalejo, el Gallego Soto, que llegó a Argentina escapando del servicio militar en España, militó activamente en la sociedad obrera de Río Gallegos y se convirtió en uno de los líderes de las huelgas en la Patagonia en $1921^{12}$. También Juana Rouco Buela, que fue una activista libertaria y una defensora de los derechos de las mujeres en Argentina y en Uruguay, principalmente. Adrián Troitińo Alcobre, panadero y canillita (vendedor callejero de prensa), fue un activo sindicalista en Buenos Aires y, sobre todo, en Montevideo. También entre Buenos Aires y Montevideo desarrolló su actividad el anarquista gallego José Tato Lorenzo. Antonio Casanova, también panadero, fue un militante sindical y anarquista en Avellaneda, antes de exiliarse en Francia bajo el nombre de Manuel Freire. Campio Carpio fue un intelectual anarquista que desarrolló su actividad en Buenos Aires, a donde había llegado con diecisiete años huyendo de su probable incorporación a la guerra de Marruecos. Son algunos ejemplos de gallegos que militaron guiados por el ideal anarquista; iremos evocando otros en las páginas siguientes.

10 Sobre la represión y el exilio cf. Grandío (2001) y Pereira y Fernández (2006).

11 Núñez Seixas (1998a, 1998b, 2014 : 89-109) y Pereira (1994) : 147-148, 160-161.

12 Sobre Antonio Soto cf. Pérez Leira (1998). 
La relación de estos gallegos libertarios con sus compatriotas en la emigración planteó, en ocasiones, algunos problemas, pues la elites emergentes - tanto de Galicia como de la emigración en los países de destino- consideraban excesivamente radical el compromiso político anarquista de algunos de sus paisanos. El ejemplo de la Argentina que nos presenta Xosé Manoel Núñez Seixas (2014: 438-444) muestra justamente este rechazo al militante anarquista gallego y la defensa de un trabajador galaico menos reivindicativo y conflictivo. Es igualmente interesante en ese sentido el silencio de la prensa gallega de la emigración ante los conflictos laborales intraétnicos que enfrentaban a patronos y a trabajadores gallegos.

Durante la emigración fue bastante habitual que los emigrantes mantuvieran contacto con Galicia; un contacto que en algunos casos va más allá del marco familiar y que alcanza el ámbito asociativo anarquista o anarcosindicalista. Esta relación con su país natal fue fundamentalmente epistolar, pero podemos percibir este contacto también a través de la prensa anarquista: bien por su suscripción a los periódicos publicados en Galicia — que reciben con regularidad-, bien por la colaboración en esos mismos periódicos desde los países de emigración en el caso de aquellos militantes más activos.

La prensa se convirtió así en un instrumento para seguir las relaciones entre los anarquistas de un lado y otro del Atlántico. En los periódicos libertarios gallegos del primer tercio del siglo xx, hasta 1936, vemos cómo las referencias a los países americanos o las contribuciones desde los países americanos son habituales. Aunque las colecciones conservadas de los periódicos de los veinticinco primeros años de siglo están bastante incompletas, el análisis de los números disponibles nos permite confirmar la relevante y bastante habitual presencia de las colaboraciones entre América y Galicia. Las colecciones que existen de la prensa de finales de los años veinte y de los años treinta son mucho más completas. Esto nos permite seguir con mayor detalle la presencia de colaboraciones desde América.

La presencia de estas informaciones es muy frecuente, lo que nos induce a pensar que, independientemente de la época tratada — primeros ańos de siglo, años diez, veinte o treinta - la presencia de América en la prensa libertaria gallega es constante y relativamente importante. Caber recordar que ya en los años noventa del siglo xix el semanario anarquista coruñés El Corsario publicaba noticias del otro lado del Atlántico gracias, en parte, al trabajo de un corresponsal en Cuba de apellido Pantín ${ }^{13}$.

De entre los periódicos analizados debemos destacar en especial el semanario anarquista Brazo y Cerebro, publicado en A Coruña entre 1935 y 1936,

13 Serrano (1987): 146. 
que cuenta una amplia cobertura y colaboraciones desde el extranjero, y que a partir de su segundo número contaba incluso con una sección titulada «Notas de América». A este interés del periódico por el continente americano debió contribuir, sin duda, la presencia en su redacción de Antonio Furnarakis, un anarquista argentino de origen griego con una trayectoria que lo llevó por varios países americanos - Argentina y Bolivia en particular- antes de instalarse en Galicia en los ańos treinta, en donde sería asesinado en 1937 en una operación de la Guardia Civil contra la resistencia libertaria al franquismo ${ }^{14}$.

La prensa libertaria de los países americanos también fue fuente de referencias para la prensa anarquista gallega. Los intercambios de periódicos facilitaban el acceso a los escritos de la prensa extranjera. Otras veces el contacto con la prensa es más directo, y en ese sentido podemos evocar el rol jugado por algunos gallegos en la prensa anarquista de distintos países americanos. Aparte de los casos ya evocados en otras partes de este artículo, podemos destacar el trabajo de militantes como Manuel Vázquez, Joaquín Hucha, Julio Camba, Antonio Loredo, José María Acha, Mariano Torrente, Joaquín Gómez o Juan Seoane en periódicos anarquistas como La Protesta, Verbo Nuevo o La Voz del Chauffeur de Argentina ${ }^{15}$; o también el de Antonio Filgueira Vieites, impulsor en Cuba del periódico La Protesta Humana ${ }^{16}$.

Analizando el conjunto de referencias de la prensa del periodo estudiado, podemos establecer una suerte de clasificación de las colaboraciones aparecidas desde o sobre América en los periódicos gallegos. Esta clasificación no responde a un orden cuantitativo o cualitativo; sin embargo, permite sintetizar los distintos tipos de artículos y de colaboraciones que muestran los estrechos intercambios entre los militantes gallegos y los de los países americanos. Esta tipología podrá, sin duda, aplicarse o adaptarse a otros estudios similares. Así, y sin que el orden de la presentación suponga un tipo de categorización cuantitativa o cualitativa, podemos apuntar:

- Las colaboraciones que los militantes gallegos enviaban a la prensa desde América.

— Los artículos de la prensa y de los militantes americanos reproducidos en los periódicos libertarios gallegos

- Las notas breves e informaciones enviadas desde América.

- Las iniciativas de apoyo solidario.

- La correspondencia y las notas administrativas.

14 Fernández y Pereira (2004): 126, e Íńiguez (2008): 654.

15 Vieites Torreiro (2001): 163.

16 Naranjo Orovio (1991): 225-226. 


\section{LAS COLABORACIONES QUE LOS MILITANTES GALLEGOS ENVIABAN A LA PRENSA DESDE AMÉRICA}

La presencia de militantes anarquistas gallegos en América fue constante a lo largo del periodo de este estudio. Algunos de ellos colaboraron con los periódicos militantes de su Galicia natal. Las colaboraciones de estos activistas en la prensa libertaria gallega nos muestran dos cosas. En primer lugar, la existencia y la persistencia de un contacto estrecho con el movimiento anarquista gallego. En segundo lugar, la voluntad de transmitir sus experiencias y sus luchas a los lectores de la prensa libertaria. El espíritu internacionalista y el ansia de superar las fronteras están así presentes en esas colaboraciones.

Podemos citar varios ejemplos de esta práctica. En Cultura Libertaria, de Ferrol, escribieron desde La Habana un tal M. Maneiro y un emigrante de Caranza (Ferrol) ${ }^{17}$. Pero la contribución más interesante en este periódico es la de Xan da Grańa, que en 1912 publicó una "Crónica de New York» en la que anunciaba su intención de mandar "de cuando en cuando" una colaboración con noticias de los Estados Unidos. Xan da Graña apuntó en ese artículo varios eventos y actividades del obrerismo organizado en Nueva York, destacando el papel de los trabajadores extranjeros — judíos, italianos y españoles principalmente- en la difusión de las ideas libertarais por el país ${ }^{18}$. Los cinco números conservados de este semanario anarquista no nos permiten saber si sus colaboraciones tuvieron la continuidad que él anunciaba.

Juan Martínez de la Grańa, «Xan da Graña» (1873-1928), era originario de A Graña, Ferrol, y desde muy joven emigró a América. Entró en contacto con el anarquismo en los círculos libertarios de La Habana, y en 1907, escapando de la represión, se instaló en Nueva York, donde siguió su actividad militante. Aparte de su trabajo de fogonero, colaboró activamente en el movimiento libertario cubano y estadounidense, manteniendo igualmente una fuerte relación con el anarquismo gallego. Sus limitaciones físicas —al parecer era miope y tartamudo - no le impidieron divulgar las ideas anarquistas, defender a los trabajadores y enfrentarse en innumerables ocasiones a los patronos y empleadores ${ }^{19}$. Junto a Pedro Esteve, fue uno de los impulsores de

17 M. Maneiro, «Al pueblo de Serantes» y «Desde La Habana», Cultura Libertaria, 16-1-1913.

18 J. Martínez de la Graña, "Crónica de New-York», Cultura Libertaria, 15-12-1912.

19 Genaro Pazos Maceiras, «Bosquejo histórico del Proletariado español en Norteamérica», Solidaridad Obrera, 29-11-1930. 
las publicaciones Cultura Proletaria y Cultura Obrera, editadas en español en la ciudad de Nueva York ${ }^{20}$.

También en 1912, La Voz del Obrero, de A Coruña, publicó una colaboración de Manuel Martínez Pérez en la que detallaba algunos aspectos de su experiencia societaria en el campo gallego y evocaba su intención de intensificar las relaciones entre los trabajadores agrarios de Cuba y de Galicia ${ }^{21}$. El coruñés Manuel Martínez Pérez pasó una parte de su vida entre Cuba y Galicia. Emigrado muy joven a América, a comienzos del siglo xx lo encontramos en la ciudad de A Coruña en la dirección del Centro de Estudios Sociales Germinal y organizando al campesinado de la comarca en la Unión Campesina, organización muy próxima del movimiento libertario local. En 1912 se encontraba de retorno en Cuba participando en el asociacionismo local y manteniendo el contacto con los anarquistas coruñeses. En 1913 fue uno de los fundadores en La Habana de la entidad llamada 13 de Octubre, una «asociación galaica» constituida con el objetivo de difundir la enseñanza racionalista $^{22}$. En los años treinta volvió a Galicia y retomó su actividad en la vida asociativa, organizando en el ámbito agrario la Unión Mutualista Campesina en las comarcas de A Coruña, Bergantiños y As Mariñas, y alentando el asociacionismo vecinal en la ciudad de A Coruña en torno a la Unión de Barrios $^{23}$.

En la década de los treinta, Genaro Pazos y Claro José Sendón enviaron crónicas desde los Estados Unidos que fueron publicadas en la Solidaridad Obrera de A Coruña. El primero de ellos escribió una serie titulada «Bosquejo histórico del proletariado español en Norteamérica», centrada especialmente en la historia de la organización sindical de los fogoneros espańoles en la costa este estadounidense a lo largo de los años diez y en la iniciativa editorial de Cultura Proletaria - con el protagonismo relevante del gallego Xan de Grańa y del catalán Jaime Vidal- ${ }^{24}$. Este trabajo es un ejemplo interesante de la memoria militante de los anarquistas españoles emigrados a los Estados Unidos y de la experiencia asociativa en los puertos de ese país. Genaro Pazos vivió una parte de su vida en la costa este de Estados Unidos. Durante la Segunda República espańola lo encontramos desarrollando su actividad

20 Las referencias a Juan Martínez de la Graña en Alonso Fernández (2006): 172; Fernández y Pereira (2004): 169, e Íñiguez (2008): 1063.

$21 \quad$ La Voz del Obrero, 11-10-1912.

22 "Abriendo brecha», La Voz del Obrero, 30-10-1913.

23 Fernández y Pereira (2004): 170-171, e Íñiguez (2008): 1074.

24 Genaro Pazos Maceiras, «Bosquejo histórico del Proletariado español en Norteamérica», Solidaridad Obrera, 15-11-1930; 29-11-1930; 13-12-1930, y 7-2-1931. 
militante en A Coruña. Murió, probablemente, en marzo de 1937 intentando huir de la ciudad de A Coruña dominada por los franquistas.

Por su parte, Claro José Sendón, a lo largo del invierno de 1931, envió varias crónicas sobre los efectos de la crisis en la sociedad estadounidense, mostrando cómo el problema del paro generaba la desesperación de muchos trabajadores en esos primeros meses de la crisis económica. Su pretensión era poner de manifiesto los efectos nefastos del capitalismo y desmontar el mito del progreso y del bienestar de los Estados Unidos ${ }^{25}$. Claro José Sendón (18991937) fue un activo militante libertario tanto en América como en Galicia. Su periplo americano lo llevó durante los años veinte de Buenos Aires a Nueva York. Regresó a Galicia en 1932 y continuó su actividad en la organización de la CNT y en la propaganda anarquista. Murió en Nueva York en el transcurso de un viaje para recabar fondos y apoyos para la Republica española ${ }^{26}$. Desde Nueva York llegó también alguna de las colaboraciones de David Alonso al semanario anarquista coruñés Brazo y Cerebro. Sus trabajos tenían un carácter doctrinal de defensa del anarquismo ${ }^{27}$.

Las colaboraciones enviadas por estos militantes gallegos en América tienen como objetivo informar sobre la actividad sindical y sobre las condiciones de vida y trabajo en sus países de acogida al otro lado del Atlántico. Muestran, además, esta voluntad de mantener el contacto con el movimiento libertario en Galicia. Sin duda, el hecho de ver regularmente a sus compañeros gallegos que trabajaban en los trasatlánticos facilitaba el intercambio de noticias, la recepción de la prensa y permitía el envío de sus contribuciones para publicar en los periódicos gallegos.

Los autores de estos artículos no eran simples afiliados de base de las organizaciones obreras, sino militantes activos con una conciencia y una formación política y sindical mucho más sólidas. Además, eran personas que ya estaban integradas en la estructura organizativa del movimiento obrero anarquista en los países de destino y, en ocasiones, también en el país de origen. Formarían parte, por lo tanto, de la elite militante activa en los

25 Claro José Sendón, «Crónicas de Yankilandia», Solidaridad Obrera, 29-11-1930; 24-1-1931; 7-2-1931, y 14-3-1931.

26 Fernández y Pereira (2004): 226-227, e Íñiguez (2008): 1612.

27 David Alonso, "Anarquismo», Brazo y Cerebro, 15-4-1936; «Sindicalismo revolucionario", Brazo y Cerebro, 1-5-1936; "Comunismo autoritario", Brazo y Cerebro, 15-61936. El primero de estos artículos fue enviado desde Nueva York. Quizá se trate de David Alonso Murillo, militante de la CNT en Vilavella (A Mezquita, Ourense) que, después de la guerra civil, se exilió en Francia y después retornó a los Estados Unidos. Una breve nota biográfica en Íniguez (2008): 63. 
sindicatos, en los grupos anarquistas, en los periódicos y en el resto de organizaciones libertarias.

\section{LOS ARTÍCULOS DE LA PRENSA Y DE LOS MILITANTES AMERICANOS REPRODUCIDOS EN LOS PERIÓDICOS LIBERTARIOS GALLEGOS}

Los periódicos gallegos también recogieron en sus páginas las colaboraciones que diferentes militantes enviaron desde América, tanto de libertarios americanos como de aquellos extranjeros que, en algún momento de sus vidas, estuvieron asentados en alguno de los países del continente. Por citar algunos ejemplos, encontramos en Cultura Libertaria un artículo de Benito Olabuénaga desde Buenos Aires que animaba a los trabajadores a la organización y a la lucha ${ }^{28}$. El periodista y dramaturgo argentino Rodolfo González Pacheco escribió desde Buenos Aires en la Solidaridad Obrera gallega y, sobre todo, en el semanario anarquista coruñés Brazo y Cerebro. Todas sus colaboraciones fueron artículos cortos de doctrina anarquista ${ }^{29}$. También desde Argentina, Mario Anderson Pacheco, el Negro Pacheco, escribió sobre la represión que sufría el movimiento anarquista en el país ${ }^{30}$.

Brazo y Cerebro publicó varios trabajos de militantes americanos. Podemos destacar la serie inédita en Espańa del periodista libertario argentino Teodoro Antillí titulada «La finalidad» o "Finalidad anarquista», donación de un grupo anarquista americano al semanario coruñés. En esta serie se reafirmaba el valor del anarquismo y la necesidad de mantener claro el objetivo del ideal libertario. La publicación de este trabajo de Teodoro Antillí fue póstuma, pues el autor había fallecido en $1923^{31}$. Desde Buenos Aires, el también argentino Julio Centenari colaboró igualmente en diferentes números del

28 Benito Olabuénaga, "A los obreros, mis hermanos», Cultura Libertaria, 15-12-1912. Según Joan Zambrana (s.f.) Olabuénaga escribió también artículos desde Buenos Aires en Tierra y Libertad entre 1913 y 1914.

29 Roberto González Pacheco, "Carteles», Solidaridad Obrera, 18-4-1931; «Carteles. Compañero; mi compañero», Brazo y Cerebro, 31-5-1935; «De hombre a hombre», Brazo y Cerebro, 15-3-1936; «iMe c... en Dios!», Brazo y Cerebro, 15-4-1936; « $V$ Vamos muchacho!», Brazo y Cerebro, 15-5-1936; «Salud a ellos», Brazo y Cerebro, 1-7-1936, y «iSalud y RS!», Brazo y Cerebro, 15-7-1936.

30 Mario Anderson, «De la dictadura argentina», Solidaridad Obrera, 13-12-1930. Mario Anderson Pacheco era un obrero y militante anarquista muy activo en la prensa libertaria durante los años veinte y treinta. Cf. Anapios (2016).

31 Teodoro Antillí, «La finalidad. I», Brazo y Cerebro, 1-8-1935; «Bis de la finalidad. II», Brazo y Cerebro, 15-8-1935; «La finalidad tercera. III», Brazo y Cerebro, 15-9-1935; 
semanario corunés, privilegiando en sus artículos la crítica a la Iglesia católica $^{32}$. La feminista portorriqueña Clotilde Betances Jaeger fue otra de las activistas americanas que escribió en Brazo y Cerebro, esencialmente sobre la guerra y el pacifismo ${ }^{33}$.

Otro nombre que encontramos en las páginas de la prensa gallega es, por ejemplo, el del anarquista italiano Luigi Fabbri, que durante su exilio en Uruguay, y poco antes de morir, publicó un artículo de crítica al fascismo y a favor de la unidad obrera ${ }^{34}$. Florentino de Carvalho, pseudónimo del emigrante asturiano Raimundo Primitivo Suárez, colaboró desde São Paulo opinando sobre las luchas sociales y el anarquismo ${ }^{35}$. Igualmente desde São Paulo, un tal Ángel Lasheras publicó algunos artículos en la prensa libertaria ${ }^{36}$. También desde Brasil, pero desde Rio de Janeiro en esta ocasión, escribió el doctor Fabio Luz sobre la libertad ${ }^{37}$. Por su parte, el semanario anarcosindicalista

«La finalidad cuarta. IV», Brazo y Cerebro, 1-10-1935; «La finalidad quinta», Brazo y Cerebro, 1-11-1935, y "La finalidad sexta», Brazo y Cerebro, 15-11-1935.

32 Julio Centenari, «El Papa y los desocupados», Brazo y Cerebro, 15-1-1936; «La crisis y la Iglesia», Brazo y Cerebro, 1-2-1936; "Crítica clerical: "La Misa”", Brazo y Cerebro, 15-2-1936; «El ateísmo es el faro de la civilización», Brazo y Cerebro, 1-4-1936; «Los jesuitas y la mujer», Brazo y Cerebro, 1-5-1936; «Sermón por el reverendo padre Vermichelli», Brazo y Cerebro, 15-5-1936; "A los mercaderes del templo», Brazo y Cerebro, 1-6-1936; «Pobres madres!», Brazo y Cerebro, 15-6-1936; «Los frailes», Brazo y Cerebro, 1-7-1936, y «El zángano», Brazo y Cerebro, 15-1-1936.

33 Clotilde Betances, «Liga de Vencedores», Brazo y Cerebro, 15-3-1936; «El plan Hoare-Laval», Brazo y Cerebro, 1-4-1936; «Italia, la guerra y la mujer», Brazo y Cerebro, 1-5-1936. Clotilde Betances escribió habitualmente en el periódico Gráfico de Nueva York y colaboró igualmente en algunas publicaciones anarquistas españolas como Estudios, de Valencia, e Iniciales, de Barcelona. Cf. Vera-Rojas (2010).

34 Luigi Fabbri, «Frente al fascismo», Brazo y Cerebro, 15-5-1935. El artículo fue escrito en Montevideo en febrero de ese año. Luigi Fabbri fue un militante y propagandista anarquista italiano que gozó de gran prestigio en los medios libertarios.

35 Florentino de Carvalho, «Al margen de las luchas sociales en le Brasil. Las cosas en su lugar. Los anarquistas y los movimientos políticos», Brazo y Cerebro, 1-10-1935. Florentino de Carvalho emigró muy joven con su familia a Brasil. Allí se convirtió en un activo militante anarquista, trabajando, sobre todo, como tipógrafo y en los oficios del puerto.

36 Ángel Lasheras, "Anarquía», Brazo y Cerebro, 1-2-1936, y «A los obreros del campo, minas, fábricas y talleres», Brazo y Cerebro, 15-6-1936. Ángel Lasheras colaboró ocasionalmente en el mismo semanario en su sección «Notas de América», y envió también contribuciones económicas.

37 Fábio Luz, «Bondad y Libertad», Brazo y Cerebro, 1-11-1935. Fábio dos Santos Lopez Luz fue un médico y escritor brasileńo, activo colaborador en la prensa de su país. 
Solidaridad reprodujo en uno de sus folletones un trabajo de Emilio López Arango, militante español instalado en Argentina y asesinado en Buenos Aires en $1929^{38}$.

En otras ocasiones encontramos en la prensa gallega llamamientos o manifiestos publicados por grupos o asociaciones libertarias. Así, por ejemplo, la Asociación Femenina contra la Guerra, de La Plata, escribió una colaboración para oponerse a la guerra y para criticar a una Asociación de Mujeres pro-Italia de la misma ciudad que quería ayudar a la Italia fascista en su guerra en Etiopía ${ }^{39}$. También podemos citar un artículo del grupo anarquista Lux, de Santiago de Chile, apelando a la abstención en las próximas elecciones en su país ${ }^{40}$. El grupo Luz, de La Habana, también envió algunas contribuciones, pero, en este caso, firmadas: la primera es un saludo firmado por un tal Charles Chan y la segunda un exhorto de carácter feminista con la firma de Luisa Michel ${ }^{41}$.

Aunque no sean especialmente abundantes, no es raro ni sorprendente encontrar la reproducción de algunos artículos de periódicos extranjeros en las páginas de los semanarios gallegos. De esta manera, en el semanario anarquista Cultura Libertaria, de Ferrol, encontramos reproducido un artículo del periódico Acción Obrera de Buenos Aires, que critica al movimiento obrero socialista ${ }^{42}$. En el mismo semanario se publicó igualmente un artículo del prestigioso periódico anarquista La Protesta, de Buenos Aires, en donde se criticaba la constante represión policial sufrida por el militante anarquista gallego Joaquín Hucha ${ }^{43}$. De La Protesta se publicó también una colaboración en 1936 en el semanario Brazo y Cerebro que animaba a no perder la perspectiva revolucionaria a largo plazo en la lucha contra el Estado y el capita ${ }^{44}$.

En el semanario coruñés anarcosindicalista Solidaridad encontramos también la reproducción de un artículo del militante uruguayo Pascual

38 Emilio López Arango, «El anarquismo. Las ideas y los hechos», Solidaridad, 3-81935 y $10-8-1935$.

39 Asociación femenina contra la guerra, «iMujeres, fuente de vida, no ayudemos a la muerte!», Brazo y Cerebro, 1-1-1936.

40 Grupo anarquista Lux, "Como en España: labor abstencionista», Brazo y Cerebro, 1-7-1935.

41 Charles Chan. "Circular n. ${ }^{\circ} 1$. Saludo», Brazo y Cerebro, 1-1-1936, y Luisa Michel, "HHasta cuándo... hermana!», Brazo y Cerebro, 15-3-1936.

42 «Socialismo conservador. El derecho de huelga en los servicios públicos», Cultura Libertaria, 2-1-1913.

43 «La libertad ciudadana», Cultura Libertaria, 1-2-1913. Joaquín Hucha era un gallego emigrado a la Argentina que desarrolló su actividad militante en este país y en Uruguay, colaborando igualmente con el anarquismo gallego.

44 «Victorias y derrotas», Brazo y Cerebro, 15-6-1936. 
Minotti ${ }^{45}$. El mismo periódico reprodujo igualmente un pequeño artículo publicado previamente en Cultura Proletaria de Nueva York, donde se denunciaba la explotación y la sumisión de los seres humanos y la necesidad de concienciarse para acabar con los abusos ${ }^{46}$. Encontramos también extractos de algunos artículos como, por ejemplo, el de la revista Nervio, de Buenos Aires, que editó Brazo y Cerebro sobre la guerra del Chaco entre Bolivia y Paraguay ${ }^{47}$.

La publicación de este tipo de contribuciones en la prensa anarquista gallega nos permite ver la ambición de sus editores para superar el marco local o nacional, abriendo así las páginas de sus periódicos a las noticias y colaboraciones desde el extranjero. Esta expresión del espíritu internacionalista era una de las características del movimiento anarquista. Las redes de sociabilidad de los gallegos en América y la facilidad y regularidad de las comunicaciones contribuyeron a la presencia de estas colaboraciones desde América en la prensa editada en Galicia.

\section{LAS NOTAS BREVES E INFORMACIONES DESDE AMÉRICA}

Mucho más habituales fueron las notas breves enviadas desde América. Tenían eminentemente un carácter informativo y mostraban algunos aspectos de la actividad de los anarquistas en los países americanos. En este apartado merece una mención particular la sección "Notas de América», que publicó con una cierta regularidad el semanario anarquista coruñés Brazo y Cerebro ${ }^{48}$. Ahí encontramos noticias enviadas desde Argentina, Brasil, Chile, Cuba o los Estados Unidos; algunas de ellas firmadas por militantes como Ángel Lasheras, Martín García, Charles Chan o un tal Nijota.

En la misma línea, aunque no centrado de manera exclusiva en el continente americano, encontramos las secciones "Crónicas internacionales» y

45 Pascual Minotti, «La inquietud», Solidaridad, 21-9-1935. Se trata de la publicación de un artículo aparecido en la Solidaridad de Montevideo. Pascual Minotti fue un militante muy activo en la Federación Obrera Regional Uruguaya; colaboró habitualmente en la revista El Hombre de Montevideo, en donde coincidió, sin duda, con el gallego José Tato Lorenzo, activista libertario que vivió la mayor parte de su vida en América del sur, en particular en Uruguay. La referencia a Minotti en Dictionnaire des militants anarchistes (s. f.), http://militants-anarchistes.info/spip.php?article12003.

46 «Hombres y Bestias», Solidaridad, 20-7-1935.

47 «De una carta del Paraguay», Brazo y Cerebro, 31-5-1935.

48 Aparece este apartado en ocho de sus veintiocho números. 
«Movimiento obrero. Del extranjero», en Acción Libertaria y en Cultura Libertaria respectivamente. En algunos casos, se presentaban aquí informaciones sobre la Argentina o los Estado Unidos ${ }^{49}$. Otras noticias aparecieron de manera aislada. Así, en octubre de 1912, un tal A. P. P. envió desde Buenos Aires una colaboración para publicar en Cultura Libertaria ${ }^{50}$. En el semanario ¡Despertad! de Vigo se publicaron también algunas noticias desde América, como la aparición, en su tercera época, del periódico mexicano Verbo Rojo, o también una información sobre el congreso de la FORA en Argentina ${ }^{51}$. Sobre la Argentina se publicó también una información en Solidaridad Obrera que denunciaba la represión que sufría el movimiento anarquista de este país ${ }^{52}$.

En otras ocasiones fueron algunas organizaciones anarquistas las que enviaron noticias para publicar en las páginas de los periódicos libertarios gallegos. Es así como encontramos varias contribuciones de la Federación Anarquista del Panamá editadas en Acción Libertaria, de Vigo, o de la Federación de Grupos Anarquistas de Lengua Castellana en los Estados Unidos, publicadas en Brazo y Cerebro. En el primer caso, la federación panameña informaba de la activa contribución económica de varios de sus grupos para financiar la puesta en marcha en España de «un establecimiento tipográfico donde se editen todas las producciones del pensamiento anarquista»; también informaba de la próxima aparición de su órgano de prensa El Único, de cuestiones organizativas y de las distintas contribuciones a favor de la prensa y la propaganda ${ }^{53}$.

En el caso de la Federación de Grupos Anarquistas de Lengua Castellana en los Estados Unidos, se anunciaba en las páginas de Brazo y Cerebro su adhesión a la Federación Anarquista Ibérica. En el mismo semanario publicó también un llamamiento a la organización de una internacional anarquista en torno a una "Federación Anarquista Universal», si bien reconocía la falta de cohesión de los grupos anarquistas en la mayor parte de países del mundo ${ }^{54}$. Estas contribuciones de los anarquistas hispanohablantes en los Estados Unidos no fueron exclusivas del semanario gallego, sino que también fueron enviadas a otras publicaciones libertarias. De todos modos, desde una perspectiva gallega, supone la divulgación entre el movimiento anarquista local de unas ideas y proyectos cuyo origen se sitúa al otro lado del Atlántico.

49 Por ejemplo, en Acción Libertaria, 6-9-1911 y Cultura Libertaria, 3-12-1912 y 1-2-1913.

50 A. P. P., «Varios asuntos», Cultura Libertaria, 3-12-1912.

51 iDespertad!, 30-5-1928 y 1-12-1928.

52 "Crónica de la Argentina», Solidaridad Obrera, 6-12-1930.

53 Acción Libertaria, 6-9-1911; 13-9-1911, y 27-9-1911.

54 Brazo y Cerebro, 1-11-1935 y 15-1-1936. 
Desde San José de Costa Rica, la comisión administrativa del Centro de Estudios Sociales Germinal saludó «a todos los compañeros del mundo» y solicitó la colaboración de los libertarios para difundir las ideas anarquistas en su país y en el área de América Central ${ }^{55}$. Desde Buenos Aires, el Comité de Relaciones Anarquista de Argentina publicó igualmente una circular anunciando el congreso de constitución de la Federación Anarquista Argentina y exponiendo la situación que se vivía en el país amenazado por la reacción y el fascismo ${ }^{56}$.

Desde Cuba, los jóvenes libertarios de La Habana mostraron también una destacada presencia en las páginas de Brazo y Cerebro. Ya en el número uno de este semanario encontramos una nota del Comité de Federaciones y Propaganda de la Juventud Libertaria; más tarde publicaron también una nota buscando relacionarse con otros jóvenes anarquistas del mundo y editaron igualmente un manifiesto al pueblo de Cuba animando a la organización de los anarquistas y a la lucha contra el nuevo Gobierno y las elites del país ${ }^{57}$. Desde La Habana se expresó también un Comité Pro-Presos y Deportados que hacía un llamamiento para apoyar la lucha por la liberación de los compañeros en prisión ${ }^{58}$.

Estas colaboraciones tienen un carácter fundamentalmente informativo. Sirven para mostrar la actividad y las iniciativas de los anarquistas en otros países y reforzaban así el espíritu militante de los lectores que percibían la existencia de un movimiento vivo y dinámico a nivel internacional.

\section{LAS INICIATIVAS DE APOYO SOLIDARIO}

La práctica de la solidaridad y del apoyo mutuo, algo habitual en el universo libertario, encontró igualmente un espacio en las páginas de la prensa. La contribución a las cajas de resistencia en los conflictos laborales, el auxilio a los huelguistas y a sus familias, el sostén a los presos o la protección a los deportados son acciones que despertaban la sensibilidad y la colaboración de los militantes. Diferentes llamamientos de este tipo son publicados en la

55 Cultura Libertaria, 1-2-1913.

56 Brazo y Cerebro, 1-11-1935.

57 "Avisos juveniles», Brazo y Cerebro, 15-5-1935; "A todos los anarquistas del orbe», Brazo y Cerebro, 15-2-1936, y «Manifiesto de la Juventud Libertaria al pueblo de Cuba», Brazo y Cerebro, 15-3-1936.

58 Comité Pro-Presos y Deportados, «Manifiesto al pueblo de Cuba», Brazo y Cerebro, 1-6-1936. 
prensa y, evidentemente, estos sobrepasan el ámbito local o regional para convertirse, en ocasiones, en movimientos internacionales de ayuda.

Por esta razón, no es en absoluto extraño encontrar en los periódicos libertarios gallegos diferentes referencias a esta cuestión. Podemos así citar, a modo de ejemplo, la recensión de un mitin organizado en Ferrol en enero de 1913 en solidaridad con «los compañeros bonaerenses» que sufrían las leyes represivas del Gobierno argentino ${ }^{59}$. Un año más tarde, La Voz del Obrero, de A Coruña, dio cuenta de un acuerdo del sindicato de camareros y cocineros marítimos de la ciudad para apoyar la demanda de sus compañeros del puerto de Buenos Aires consistente en rechazar los trabajos en tierra firme, fuera de sus navíos, en los puertos argentinos ${ }^{60}$.

Este mismo periódico, unos años más tarde, apoyó la campaña para conseguir que el Gobierno cubano indultase al joven emigrante gallego Benito Barreiro, condenado a más de catorce años por haber matado en una trifulca a su capataz, y animaba a las sociedades obreras coruñesas a cooperar en esta iniciativa ${ }^{61}$. A veces, la demanda de colaboración era para poner en marcha nuevas publicaciones. Este es el caso, por ejemplo, de un grupo de militantes libertarios de Montevideo que solicitaban ayuda para publicar una revista anarquista ${ }^{62}$.

Uno de los colectivos que recibió a menudo el apoyo de los militantes obreros fue el de los deportados. La deportación era uno de los recursos utilizados por las autoridades de un país para expulsar a individuos por razones políticas, sociales u otras. Algunas de estas deportaciones se efectuaban en barcos que arribaban a los puertos gallegos. Es el caso relatado por el vigués Acción Libertaria de ocho obreros que llegaron desde Cuba al puerto de Vigo y que fueron «acogidos fraternalmente» por los trabajadores de la ciudad. Denunciaba el periódico tanto la acción de las autoridades cubanas como de las españolas, por tratar como delincuentes "perniciosos» a personas que no estaban acusadas de delito alguno ${ }^{63}$.

En la Solidaridad Obrera de A Coruña, tres militantes deportados escribieron un mensaje a la sociedad de resistencia «Unión de Chauffeurs» de Buenos Aires para darles los contactos de los comités Pro-Presos y Deportados de las ciudades de Vigo y A Coruña ${ }^{64}$. Y en Brazo y Cerebro, una nota invitaba a

\footnotetext{
59 "Contra las leyes de represión. Un mitin», Cultura Libertaria, 16-1-1913.

60 «Reuniones y acuerdos», La Voz del Obrero, 30-1-1914.

61 «Apelando a la solidaridad obrera», La Voz del Obrero, 11-6-1917.

62 "Esfuerzo", Brazo y Cerebro, 15-3-1936.

63 Acción Libertaria, 3-11-1911.

64 Solidaridad Obrera, 19-8-1933.
} 
los deportados de Argentina y de Uruguay «accidentalmente residentes en A Coruña» a darse a conocer para establecer una relación con los militantes en la misma situación ${ }^{65}$. La atención que la prensa libertaria gallega prestó a los deportados no era algo nuevo, pues en 1905 el periódico corunés Germinal ya había protestado contra las deportaciones y la represión ejercida sobre el movimiento obrero por el Gobierno argentino ${ }^{66}$.

Las grandes campañas de solidaridad internacional también encontraron eco en la prensa militante gallega. Así, el semanario La Lucha, de Ferrol, reprodujo en noviembre de 1920 el «Manifiesto a los trabajadores del mundo» enviado desde Boston (Estados Unidos) en apoyo a los anarquistas italianos Sacco y Vanzetti, detenidos ese mismo ańo y ejecutados en 1927. Apuntar que el manifiesto estaba firmado, en nombre del Comité de Defensa Pro-Presos de Boston, por el emigrante gallego José Marinero ${ }^{67}$.

El caso de Simón Radowitzky también encontró amplio eco en varios periódicos libertarios gallegos. Simón Radowitzky fue un militante anarquista que, en noviembre de 1909, asesinó al jefe de la policía de Buenos Aires -Ramón Falcón- en represalia por la represión ejercida durante la Semana Roja que la capital argentina había vivido en ese mismo año. Simón Radowitkky fue condenado a cadena perpetua y permaneció varios años en el penal de Ushuaia. En los años veinte, se puso en marcha una campaña de solidaridad para reclamar su indulto; que fue finalmente concedido en 1930. Condenado al exilio, Radowitzky se instala en Uruguay. Aquí, el Gobierno trató de expulsarlo en 1934 y lo encerró en prisión; lo que generó una nueva iniciativa internacional para liberarlo.

Una referencia a Radowitzky en la prensa gallega aparece en el semanario vigués ;Despertad! en diciembre de 1928 . El editorial del periódico se sumaba a las demandas de libertad para quien era considerado «un vengador del pueblo ultrajado» y "una víctima de eso que llaman justicia histórica» ${ }^{68}$. Casi tres años más tarde, la Solidaridad Obrera de A Coruña reprodujo

65 Se pide escriban a Rogelio López en A Coruña. Brazo y Cerebro, 15-1-1936. Las respuestas no se hicieron esperar, tal y como se puede ver en el acuse de recibo publicado unas semanas más tarde. Cf. Brazo y Cerebro, 1-4-1936.

66 Vieites Torreiro (2001): 179.

67 La Lucha, 20-11-1920. José Marinero era el pseudónimo de Francisco López García, un gallego emigrado a los Estados Unidos que desarrolló una destacada actividad militante en los medios anarquistas hispanos junto a Pedre Esteve. Fue muy activo en la campaña de apoyo a Sacco y Vanzetti. Sobre Francisco López García cf. Íniguez (2008): 960.

68 ¡Despertad!, 15-12-1928. 
igualmente una carta de Simón Radowitzky, escrita apenas liberado, saludando a los delegados de la AIT que se iban a reunir en Madrid en el cuarto congreso de la organización y agradeciendo el apoyo ofrecido por los anarquistas del mundo para su liberación ${ }^{69}$.

En 1935, Brazo y Cerebro publicó dos notas ensalzando la figura de Radowitzky y animando a participar en la campaña de solidaridad para liberarlo del penal en el que se encontraba detenido en la Isla de Flores, en Uruguay, y de la deportación que el Gobierno de este país le quería imponer ${ }^{70}$. Meses más tarde, este mismo semanario publicó una carta abierta del propio Simón Radowitzky en la que rechazaba el apoyo de los comunistas en su campaña de solidaridad, recordando a todos los anarquistas la responsabilidad de aquellos en las represalias al movimiento libertario en la Unión Soviética ${ }^{71}$.

Otro caso que tuvo repercusión en la prensa libertaria gallega fue el de los presos de Bragado, en Argentina. En este proceso, tres anarquistas - Pascual Vuotto, Reclús de Diago y Santiago Mainini- fueron condenados por un atentado que no habían cometido contra el político conservador José María Blanch. Se inició entonces una campaña internacional de solidaridad para apoyar a estos trabajadores; campaña de la que se hizo eco, una vez más, el periódico Brazo y Cerebro para presionar a las autoridades judiciales argentinas ${ }^{72}$.

También tuvo un eco importante en la Solidaridad Obrera de A Coruña la deportación de militantes libertarios como consecuencia de la represión ejercida por el nuevo Gobierno del general golpista José Félix Uriburu contra el movimiento obrero argentino. Una parte de estos deportados llegaron a Galicia por el puerto de Vigo, entre ellos José Vendrell, Jerónimo Rodríguez, Avelino López, Ramón Cajide, Florentino Carballo y Manuel A. Nieto. Uno de ellos denunció, justamente, «el terror y el espanto» que se estaba viviendo en Argentina desde hacía unas semanas ${ }^{73}$.

69 Simón Radowitzky, «Un saludo de Radowisky (sic) ante el cuarto congreso de la AIT», Solidaridad Obrera, 30-5-1931.

70 "Urge una campaña internacional en defensa de Simón Radowisky (sic)», Brazo y Cerebro, 31-5-1935. «Por la libertad de Simón Radowitzky», Brazo y Cerebro, 1-11-1935.

71 La carta fue escrita en prisión en abril de 1936 y publicada unas semanas más tarde en Brazo y Cerebro. Cf. Simón Radowitzky, "Carta abierta», Brazo y Cerebro, 1-6-1936.

72 «Sobre la campańa por los presos de Bragado», Brazo y Cerebro, 1-11-1935.

73 "De la dictadura argentina», Solidaridad Obrera, 15-11-1930 y Un deportado, «Pedido de solidaridad», Solidaridad Obrera, 6-12-1930. Jerónimo Rodríguez Sánchez militó en los sindicatos del calzado y de choferes de Buenos Aires e integró el grupo editor de La Protesta. Después de su deportación en 1930 retornó a la Argentina. Desde finales de 1936 participa en la guerra civil; tras un periodo en el exilio en Francia, retornó a 
En todos los casos, las noticias relativas a las iniciativas solidarias tienen un carácter informativo y de apoyo a los compañeros en dificultad. Apenas se desarrollan reflexiones y análisis de las situaciones expuestas, lo que viene a resaltar el aspecto propagandístico y de ayuda mutua de este tipo de información en los periódicos analizados. Los militantes anarquistas eran muy sensibles a la acción solidaria y al apoyo mutuo. La precariedad habitual en sus condiciones de vida — bajos salarios, inestabilidad profesional, recursos familiares insuficientes- y la represión regular que sufrían por parte de las autoridades — detenciones, condenas a prisión, cierre de sindicatos, censura de prensa- favorecían estas prácticas. De ahí que no resulte en absoluto extraño la presencia importante de estas noticias en los periódicos libertarios.

\section{LA CORRESPONDENCIA Y LAS NOTAS ADMINISTRATIVAS}

Estas secciones eran bastante habituales en la prensa que estamos tratando. Su objetivo era, básicamente, reproducir mensajes, acuses de recibo, donativos solidarios a los periódicos y otro tipo de referencias a los intercambios con la prensa. El interés de este tipo de notas es que nos permiten hacer un seguimiento de los lectores y suscriptores en el extranjero e, indirectamente, de la presencia de determinados militantes y simpatizantes en diferentes ciudades o países.

En el caso que nos ocupa, podemos ver las relaciones de algunos de los periódicos anarquistas gallegos con los países de América. Así, Acción Libertaria y Cultura Libertaria, en 1911 y 1912, mantienen una activa correspondencia con Panamá, Nueva York, Buenos Aires o La Habana. Igualmente, en Brazo y Cerebro una muy importante cantidad de referencias en estas secciones corresponden a direcciones y contactos de ciudades de diversos países americanos: Buenos Aires, Rosario, Santa Fe, Montevideo, São Paulo, Rio de Janeiro, Guayaquil, Lima, Medellín, México, La Habana, Nueva York, Newark (Nueva Jersey), Detroit, Canto (Ohio) o Colón (Panamá) forman parte de los lugares de intercambio de este semanario anarquista.

Argentina en 1946. Avelino López era miembro del sindicato de choferes de Buenos Aires. Tras su deportación en 1930 retorna a América, en este caso a Montevideo. Manuel (o Miguel) A. Nieto y Florentino Carballo eran dos gallegos militantes de la FORA. Ramón Cajide era miembro del sindicato de panaderos de Buenos Aires; tras su deportación en 1930 militó en las filas de la CNT en Galicia. Cf. Íniguez (2008): 291, 329, 947, 1206, 1484, y Vieites Torreiro (1998): 106. 


\section{CONCLUSIONES}

Para concluir, debemos recordar la existencia de un nexo de unión fuerte entre el movimiento libertario gallego y los movimientos libertarios de diferentes países de América. En esta relación jugaron un papel importante los emigrantes gallegos que se instalaron, en algún momento de sus vidas, en estos países. Las razones de esta emigración son variadas: búsqueda de trabajo y de mejores salarios, evitar el cumplimiento del servicio militar en España o la huida por causa de la represión de algunos movimientos sociales. Muchos de estos emigrantes militaron en los sindicatos en sus países de destino y participaron en las iniciativas desarrolladas por las redes anarquistas en el continente americano. Una parte de ellos ya tenía una experiencia previa en el asociacionismo obrero en Galicia. Otros continuaron su militancia una vez retornados integrándose, o reintegrándose, al entramado organizativo existente en el país.

De manera complementaria a la actividad de los emigrantes, también debemos destacar el rol de los trabajadores que visitaban regularmente los países americanos empleados en los barcos que cubrían el trayecto entre Galicia y América. $\mathrm{Su}$ labor de enlace y de transporte de prensa, publicaciones u otros documentos se antoja fundamental a la hora de alimentar las redes de comunicación militantes.

La prensa fue una de estas actividades en las que se integraron los libertarios gallegos más combativos. Por esta razón es posible seguir la relación entre el anarquismo gallego y el de los países americanos a través de los periódicos libertarios editados en Galicia. Eso muestra el importante papel de la prensa como catalizador de una dinámica militante que iba más allá del ámbito local y que, en el caso que nos ocupa, superaba las fronteras nutriendo las redes transnacionales del movimiento anarquista.

Este contacto entre ambos lados del Atlántico y la presencia habitual de América en las páginas de los periódicos libertarios le confiere a la prensa anarquista gallega un carácter transnacional evidente. Este carácter transnacional no se expresa de manera exclusiva por las relaciones Galicia-América, ya que en los distintos periódicos encontramos noticias y referencias a otros países del mundo, fundamentalmente europeos, en los que Portugal ocupa también un lugar de preferencia en razón de su cercanía física y de sus fuertes relaciones transfronterizas con Galicia.

Las colaboraciones que encontramos en la prensa libertaria gallega son variadas, destacando especialmente aquellas en forma de artículos escritos por gallegos emigrados o por militantes libertarios americanos. Estos autores integraban las organizaciones anarquistas en sus países de destino y serían, de hecho, líderes y activistas con experiencias y trayectorias militantes contrastadas. 
También resultan relevantes en la prensa las iniciativas de solidaridad apoyadas por los anarquistas gallegos. Eso, junto con los intercambios de noticias, prensa y donativos solidarios, son un ejemplo de la existencia de una comunicación fluida entre Galicia y América, y una muestra de la práctica del internacionalismo proletario, bandera de la lucha obrera contra la explotación de los trabajadores. Un internacionalismo complementario a la voluntad de los gallegos en la emigración de mantener y reforzar el contacto y la relación con el movimiento libertario de su país, así como de transmitir su experiencia en sus países de acogida.

Los objetivos de las contribuciones analizadas son fundamentalmente de tipo informativo y propagandístico. Por un lado, la difusión de noticias e iniciativas es una de las finalidades del discurso periodístico. Por otro lado, el aspecto propagandístico es propio de la prensa militante que estamos tratando $y$, en el que caso que hemos tratado, busca reforzar el espíritu militante de los lectores y desarrollar las ideas anarquistas y los valores y principios asumidos por los libertarios. El carácter informativo y propagandístico prima sobre el aspecto analítico, si bien algunos trabajos se orientan hacia una reflexión ideológica anarquista más profunda.

El contacto por medio de la prensa es un ejemplo del carácter transnacional de la práctica militante libertaria. Las relaciones expresadas en los periódicos libertarios responden a iniciativas individuales o de grupos y organizaciones de base. Son una muestra del funcionamiento reticular del anarquismo y un ejemplo de la dinámica internacional del movimiento libertario. Son igualmente el reflejo de las trayectorias vitales de una serie de militantes que vivieron en sus carnes la experiencia migratoria, unas veces temporal, otras veces definitiva, pero a menudo manteniendo una relación con el anarquismo organizado en su Galicia natal. Unos militantes que contribuyeron con su acción a tejer y a enriquecer los lazos de una sólida red anarquista de carácter transnacional.

\section{Bibliografía}

Alonso Fernández, B. (2006). Obreiros alén mar. Mariñeiros, fogoneiros e anarquistas galego en New York. Vigo: Promocións Culturais Galegas.

Anapios, L. (2016). Prensa y estrategias editoriales del movimiento anarquista en la Argentina de entreguerras. Anuario del Instituto de Historia Argentina, 16 (2). Disponible en: http://www.anuarioiha.fahce.unlp.edu.ar/article/view/IHAe025/7864.

Briallos, A. (2003). Vigo 1936. La contribución libertaria a la resistencia contra el alzamiento militar de 1936 en Vigo. A Coruña: Ateneu Libertário Ricardo Mella.

Dictionnaire des militants anarchistes (s.f.). Pascual Minotti. Disponible en: http://militants-anarchistes.info/. 
Fernández, E. y Pereira, D. (2004). O anarquismo na Galiza. Apuntes para unha enciclopedia. Santiago de Compostela: Edicións Positivas.

Freán Hernández, Ó. (2013). A revolución escrita. A prensa obreira galega (1866-1936), Binges: Éditions Orbis Tertius.

González López, E. (1987). Memorias de un estudiante liberal (1903-1931). Sada: Ediciós do Castro.

Grandío Seoane, E. (2001). Vixiancia e represión na Galicia da guerra civil. O «Informe Brandariz», (A Coruña, 1937). Sada: Ediciós do Castro.

Guardia, C. de la y Pan-Montojo, J. (1998). Reflexiones sobre una historia transnacional. Studia Historica. Historia Contemporánea, 16, 9-31.

Íñiguez, M. (2008). Enciclopedia histórica del anarquismo español. Vitoria-Gazteiz: Asociación Isaac Puente.

Iriye, A. (2013). Réflexions sur l'histoire globale et transnationale. Cahiers d'Histoire. Revue d'Histoire critique, 121, 89-106. Disponible en: https://chrhc.revues.org/3174.

Naranjo Orovio, C. (1991). La inmigración española y el movimiento obrero cubano, 1900 1925. Arbor: Ciencia, Pensamiento y Cultura, 547-548, 217-240.

Núnez Seixas, X. M. (1998a). Emigrantes, caciques e indianos. O influxo sociopolítico da emigración transoceánica en Galicia, 1900-1930. Vigo: Edicións Xerais.

— (1998b). Retornados e inadaptados: el «americano gallego, entre mito y realidad (18801930). Revista de Indias, 58 (214), 555-593. Disponible en: https://doi.org/10.3989/ revindias.1998.i214.748.

- (2014). Las patrias ausentes: estudios sobre historia y memoria de las migraciones ibéricas (1830-1960). [Oviedo]: Genueve Ediciones.

Pereira, D. (1994). A CNT na Galicia, 1922-1936. Santiago de Compostela: Laiovento.

Pereira, D. y Fernández, E. (2006). O movemento libertario en Galiza (1936-1976). Vigo: Promocións Culturais Galegas.

Pérez Leira, P. (coord.) (1998). O galego Soto. Lider da Patagonia rebelde. Vigo: Edicións Xerais de Galicia.

Serrano, C. (1987). Le tour du peuple. Crise nationale, mouvements populaires et populisme en Espagne (1890-1910). Madrid: Casa de Velázquez.

Sueiro Seoane, S. (2013). Las redes anarquistas transnacionales entre los siglos XIX y XX. Alcores. Revista de Historia Contemporánea, 15, 13-19.

Vera-Rojas, M. T. (2010). Polémicas, feministas, puertorriqueńas y desconocidas: Clotilde Betances Jaeger, María Mas Pozo y sus "Charlas femeninas» en el Gráfico de Nueva York, 1929-1930. Centro Journal, 22 (2), 5-33.

Vieites Torreiro, D. (1998). O anarquismo na Arxentina: a participación dos inmigrantes galegos, 1880-1930. En L. Pérez Leira, (coord.), O galego Soto. Lider da Patagonia rebelde (pp. 57-107). Vigo: Edicións Xerais de Galicia.

- (2001). La participación de los gallegos en el movimiento obrero argentino (18801930). En X. M. Núnez Seixas (ed.). La Galicia Austral. La inmigración gallega en la Argentina. Buenos Aires: Editorial Biblos.

Zambrana, J. (s.f.) El anarquismo organizado en los origenes de la CNT. Tierra y Libertad, 1910-1919. Disponible en: http://bit.ly/2Mwz7Ds. 